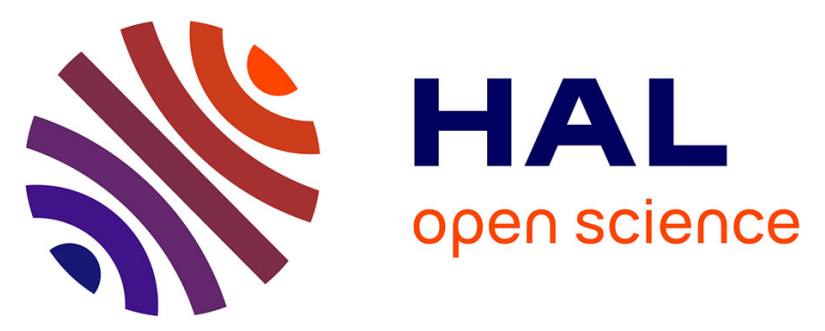

\title{
Ultrabright terbium nanoparticles for FRET biosensing and in-situ imaging of epidermal growth factor receptors
}

Cyrille Charpentier, Vjona Cifliku, Joan Goetz, Aline M. Nonat, Clemence

Cheignon, Marcelina Cardoso dos Santos, Laura Francés-Soriano, Ka-Leung

Wong, Loic Joanny Charbonnière, Niko Hildebrandt

\section{To cite this version:}

Cyrille Charpentier, Vjona Cifliku, Joan Goetz, Aline M. Nonat, Clemence Cheignon, et al.. Ultrabright terbium nanoparticles for FRET biosensing and in-situ imaging of epidermal growth factor receptors. Chemistry - A European Journal, 2020, 26 (64), pp.14602-14611. 10.1002/chem.202002007. hal-02873469

HAL Id: hal-02873469

https://hal-normandie-univ.archives-ouvertes.fr/hal-02873469

Submitted on 15 Sep 2020

HAL is a multi-disciplinary open access archive for the deposit and dissemination of scientific research documents, whether they are published or not. The documents may come from teaching and research institutions in France or abroad, or from public or private research centers.
L'archive ouverte pluridisciplinaire HAL, est destinée au dépôt et à la diffusion de documents scientifiques de niveau recherche, publiés ou non, émanant des établissements d'enseignement et de recherche français ou étrangers, des laboratoires publics ou privés. 


\section{Ultrabright terbium nanoparticles for FRET biosensing and in- situ imaging of epidermal growth factor receptors}

Cyrille Charpentier, ${ }^{a \neq}$ Vjona Cifliku, ${ }^{b, c t}$ Joan Goetz, ${ }^{a, d}$ Aline Nonat, ${ }^{a}$ Clémence Cheignon, ${ }^{a}$ Marcelina Cardoso Dos Santos, ${ }^{b}$ Laura Francés-Soriano, ${ }^{c}$ Ka-Leung Wong, ${ }^{d}$ Loïc J. Charbonnière $^{a, *}$ Niko Hildebrandt, ${ }^{b, c *}$

Addresses

a) Equipe de synthèse pour l'analyse (SynPA), Institut Pluridisciplinaire Hubert Curien (IPHC), UMR 7178, CNRS, Université de Strasbourg, 67087 Strasbourg Cedex, France.

b) Institute for Integrative Biology of the Cell (I2BC), Université Paris-Saclay, Univeristé ParisSud, CNRS, CEA, 91405 Orsay Cedex, France.

c) nanoFRET.com, Laboratoire COBRA (Chimie Organique, Bioorganique, Réactivité et Analyse), Université de Rouen Normandie, CNRS, INSA, 76821 Mont-Saint-Aignan Cedex, France.

d) Department of Chemistry, Hong Kong Baptist University, Hong Kong SAR, Hong Kong

t: These authors contributed equally.

* : niko.hildebrandt@univ-rouen.fr, $\underline{\text {.charbonn@unistra.fr }}$

Abstract. Lanthanide-doped nanoparticles (LnNPs) have become an important class of fluorophores for advanced biosensing and bioimaging. LnNPs that are photosensitized by surface-attached antenna ligands can possess exceptional brightness. However, their functional bioconjugation remains an important challenge for their translation into bioanalytical applications. To solve this problem, we designed a ligand that can be simultaneously applied as efficient light harvesting antenna for Tb surface ions and strong linker of biomolecules to the LnNPs surfaces. To demonstrate generic applicability of the photosensitized TbNPbioconjugates, we applied them in two prototypical applications for biosensing and bioimaging. 
First, in-solution biorecognition was shown by time-resolved Förster resonance energy transfer (FRET) between streptavidin-functionalized TbNPs to biotinylated dyes (ATTO 610). Second, in-situ detection of ligand-receptor binding on cells was accomplished with TbNP-antibody (Matuzumab) conjugates that could specifically bind to transmembrane epidermal growth factor receptors (EGFR). High specificity and sensitivity were demonstrated by time-gated imaging of EGFR on both strongly (A431) and weakly (HeLa and Cos7) EGFR-expressing cell lines, whereas non-expressing cell lines (NIH3T3) and EGFR-passivated A431 cells did not show any signals. Despite the relatively large size of TbNP-antibody conjugates, they could be internalized by A431 cells upon binding to extracellular EGFR, which showed their potential as bright and stable luminescence markers for intracellular signalling.

Keywords: Lanthanide nanoparticles, brightness, time-resolved detection, bio-labeling, FRET, luminescence microscopy, fluorescence, terbium, EGFR, bioconjugation,

\section{Introduction}

With the ever increasing needs for early detection, improved sensitivity and multiplexing capacity, luminescent nanoparticles (NPs) have become tools of choice in the pool of probes for bioanalysis. ${ }^{[1]}$ Semiconductor quantum dots (QDs), have played a crucial role in that field, revealing excellent brightness properties applicable to numerous analytical issues. ${ }^{[2]}$ Beyond QDs, the family of luminescent NPs continues to grow with the advents of, e.g., dyedoped polymeric NPs, ${ }^{[3]}$ nanopolymers ${ }^{[4]}$ or upconverting NPs. ${ }^{[5]}$ Lanthanide (Ln) based NPs, displaying line like spectral emission signatures, very long excited state lifetimes for autofluorescence free time-gated detection, and emission throughout almost all the UV-Vis-NIR domain, were shown to be particularly appealing for various bioanalytical applications, ${ }^{[6]}$ including in-solution assays ${ }^{[7]}$ as well as in-vitro and in-vivo imaging. ${ }^{[3,8]}$ However, in contrast to QDs, for which the quantum confinement impeded them with very high brightness, the Laporte forbidden character of $f$ - $f$ electronic transitions of $\operatorname{Ln}^{[9]}$ severely impact the absorption properties, and concomitantly their brightness. To overcome this issue, the antenna effect, consisting in embedding $\mathrm{Ln}^{3+}$ cations in the cavity of photosensitizing ligands for Ln molecular complexes, ${ }^{[10]}$ was extended to Ln based NPs ${ }^{[11]}$ and we recently demonstrated that the rational design of surface capping antenna ligands can afford ultra-luminescent LnNPs that combine exceptional spectroscopic properties, with brightness exceeding those of classical QDs. ${ }^{[12]}$ 
While such surface-photosensitized LnNPs were shown to be bright, stable, and biocompatible, their bioanalytical application has been limited to proof of concept studies, in which the LnNPs were used for optical imaging without bioconjugation. ${ }^{[3,12]}$ However, stable and robust labeling of biomolecules to NP surfaces (functional nanobioconjugates) ${ }^{[13]}$ and efficient biological recognition for biosensing in solution and imaging on and in cells are among the most important prerequisites to implement NPs into actual bioanalytical applications.

To address the challenge of biologically functional surface-photosensitized LnNPs in a most straightforward manner, we synthesized and characterized ligands that can be simultaneously used for both bioconjugation and photosensitization. Activated functional groups were used for covalent binding of the ligands to amine or sulfhydryl groups on biomolecules. These antenna-ligand-labeled biomolecules were then attached to $\mathrm{Tb}$-doped $\mathrm{LaF}_{3}$ NPs (TbNPs) via coordination between the chelating antenna functions of the ligand and $\mathrm{Tb}^{3+}$ ions on the TbNP surface. Thus, surface attachment of biomolecules directly resulted in photosensitization of the TbNPs, such that the biomolecules could "switch on" the TbNP photoluminescence (PL) and lead to ultra-bright luminescent TbNPs for specific biological recognition (Figure 1). To demonstrate the functionality of the TbNP-bioconjugates, we applied them to two prototypical biosensing approaches. First, time-resolved and separationfree FRET (Förster resonance energy transfer) bioassays showed that biotinylated organic dyes (ATTO 610) could efficiently bind to streptavidin (sAv)-functionalized TbNPs and that the biotin-sAv recognition resulted in efficient FRET from photosensitized $\mathrm{Tb}^{3+}$ ions to the biotinylated dyes. Second, TbNPs conjugated with Matuzumab antibodies (ABs) against the epidermal growth factor receptor (EGFR) were used to visualize EGFR expression and internalization by different cell lines with time-gated PL microscopy. Careful PL analysis in both applications showed that these TbNP-bioconjugates can be efficiently implemented into real bioanalytical applications in both biosensing and bioimaging. 

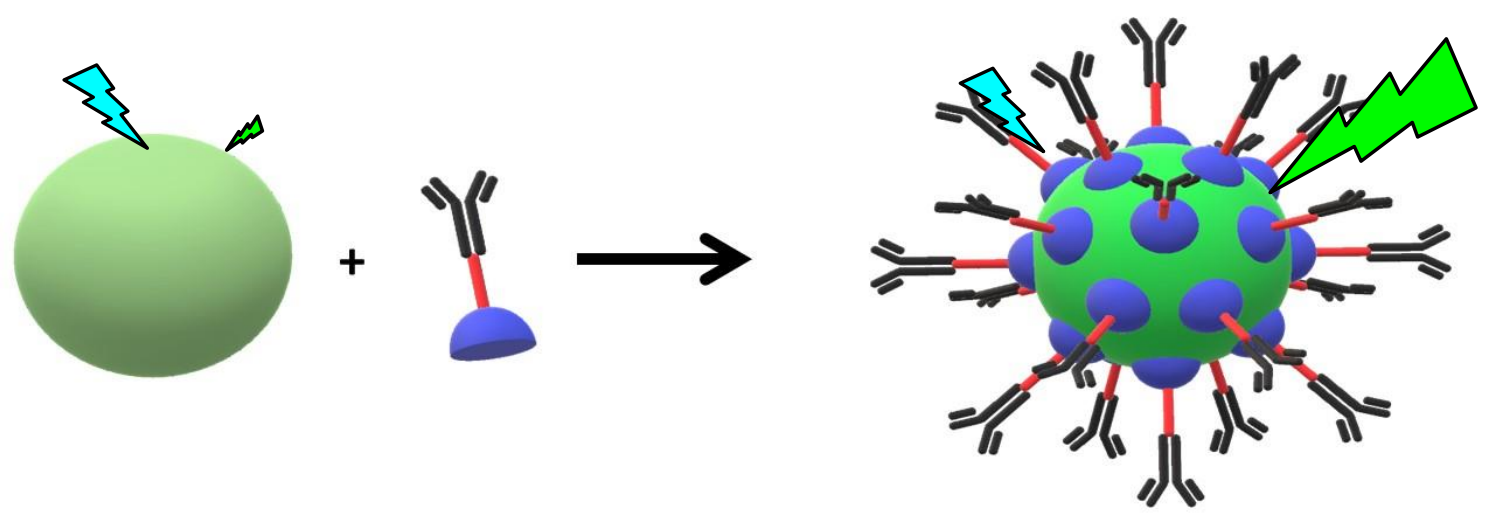

Biofunctionalized

Tb NPs Photosensitizing ligands

Biofunctionalized Photosensitized Tb NPs

Figure 1. Principle of biofunctionalized ultra-bright Ln nanoparticles. Without antenna-ligandfunctionalized biomolecules (in this case antibodies - AB), TbNPs do not emit significant PL upon UV excitation (left). Efficient coordination of the AB-ligand conjugates to $\mathrm{Ln}^{3+}$ ions on the TbNP surface leads to bright photosensitized Tb PL and biofunctional NP surfaces.

\section{Results and discussion}

Synthesis of functionalizable surface capping photosensitizing ligands and formation of

TbNPs. Based on prior works in the field of luminescent Tb complexes, ${ }^{[14]}$ we have demonstrated that hydroxy-isophthalic acid can be an excellent surface photosensitizing ligand for $\mathrm{Tb}$ doped $\mathrm{LaF}_{3} \mathrm{NPs} .{ }^{[11]}$ Additionally, the introduction of a linker between two such units afforded a supplementary stabilization of the coordination at the surface. In order to render such bis-chelating units linkable to any compound of interest, the linker between the two units was modified to introduce an activated function (noted by the symbol * after the ligand) that should further react with amine $\left(\mathrm{L}_{1} *\right)$ or thiol functions $\left(\mathrm{L}_{2} *\right)$. The synthetic methodology for the preparation of the activated ligands is depicted in Scheme 1. 


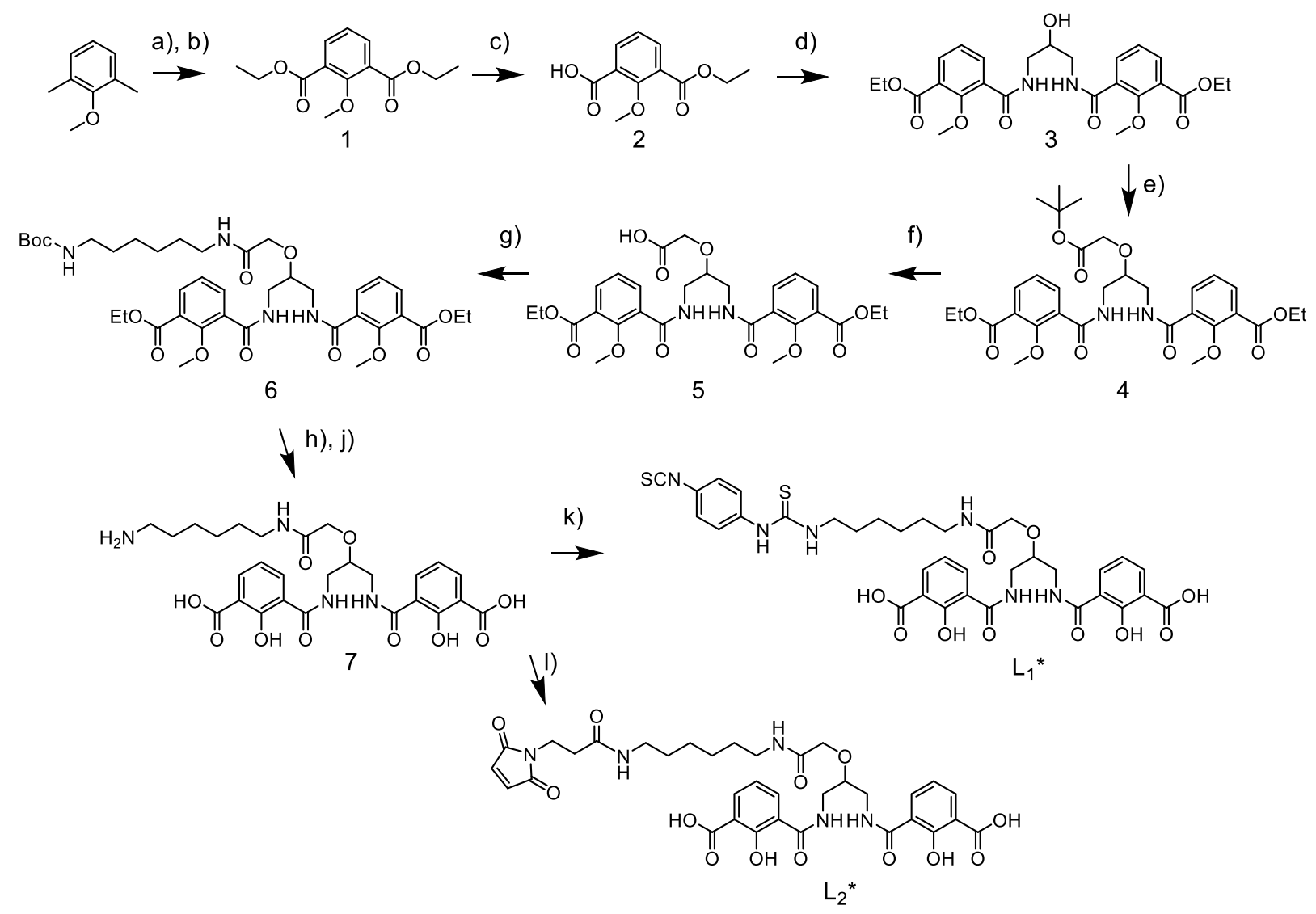

Scheme 1. Synthesis of the activated ligands for the surface functionalization of LnNPs.

a) $\mathrm{KOH}, \mathrm{KMnO}_{4}, \mathrm{H}_{2} \mathrm{O}, 110^{\circ} \mathrm{C}$. b) $\mathrm{H}_{2} \mathrm{SO}_{4}, \mathrm{EtOH}, 90^{\circ} \mathrm{C}, 79 \%$ (a+b). c) $\mathrm{KOH}, \mathrm{EtOH}, 90^{\circ} \mathrm{C}, 76 \%$ d) EDCI, $\mathrm{HOBt}$, $\mathrm{Et}_{3} \mathrm{~N}, 0^{\circ} \mathrm{C}, 74 \%$. e) $t$-BuOK, THF, r.t., $51 \%$. f) TFA, DCM, $50^{\circ} \mathrm{C}, 70 \%$. g) EDCI, HOBt, $\mathrm{Et}_{3} \mathrm{~N}, 0^{\circ} \mathrm{C}, 61 \%$. h) $\mathrm{BBr}_{3}$, DCM, r.t.. j) $\mathrm{NaOH}, \mathrm{EtOH}, 90^{\circ} \mathrm{C}, 80 \%(\mathrm{~h}+\mathrm{j})$. k) bis-isothiocyanate, $\mathrm{Et}_{3} \mathrm{~N}$, DMF, r.t., $88 \%$. 1) N-methylmorpholine, DMF, r.t., $73 \%$.

Briefly, 2,6-dimethyl-anisol was oxidized by $\mathrm{KMnO}_{4}$, followed by a sulphuric acid catalyzed esterification of the formed acid with ethanol to afford the diester $\mathbf{1}$, which was subjected to a controlled single saponification using substoechiometric amounts of $\mathrm{KOH}$. A double peptide coupling reaction was performed using EDCI in the presence of HOBt to couple two chromophoric units to a 2-hydroxy-1,3-propylene diamine spacer. The alcohol function of compound $\mathbf{3}$ was deprotonated to react in a Williamson nucleophilic substitution with $t$-butylbromoacetate, leading to the intermediate 4 , which, after deprotection of the $t$-butyl protecting group affording compound $\mathbf{5}$, was coupled to a mono-protected hexylenediamine, ${ }^{[15]}$ in a second peptidic coupling reaction. The Boc protection of the amine function of the as-obtained intermediate compound $\mathbf{6}$ was removed by acidic treatment with trifluoroacetic acid and the amine was engaged into a coupling reaction with 1,4-bis-benzene-isothiocyanate to afford the amine reactive ligand $\mathrm{L}_{1}$ * ligand or with the NHS ester of N-propionic-maleimide to give the 
thiol reactive ligand $\mathrm{L}_{2} *$. The UV-Vis absorption spectra and excitation and emission spectra of $\mathrm{L}_{1} *$ and $\mathrm{L}_{2} *$ are presented in Figures $\mathbf{S 2 4}$ and $\mathbf{S 2 5}$ (Supplementary Information).

TbNPs were synthesized according to previously published procedures and their shape and composition were characterized by TEM (Figure S26, Supplementary Information), DLS and ICP-MS analysis. ${ }^{[12]}$ The concentration of the NPs was determined (following the previously published method $)^{[12]}$ using the average size of the NPs as determined by TEM measurement, the density of $\mathrm{La}_{0 .} \mathrm{Tb}_{0.1} \mathrm{~F}_{3}$ calculated as the percentage weighted density of $\mathrm{LaF}_{3}$ and $\mathrm{TbF}_{3}$, and the total amount of $\mathrm{La}$ (or $\mathrm{Tb}$ ) amount in the solution, as determined by ICP-MS analysis.

Spectrofluorimetric titration of TbNPs by the activated ligand $\mathbf{L}_{1} *$. In a following step, the surface coordination of the NPs by the activated ligand was investigated by a combination of UV-Vis absorption spectroscopy and PL titration experiments. Briefly, increasing quantities of ligands were added to a nanomolar solution of the TbNPs. Figure S27 (Supplementary Information) represents the evolution of the absorption spectra of the solution as a function of added ligands while Figure 2 shows the evolution of the emission spectra and the variations of the $\mathrm{Tb}$ centred emission at $545 \mathrm{~nm}$ upon excitation into the ligand absorption band at $337 \mathrm{~nm}$ as a function of the number of ligands per NPs.
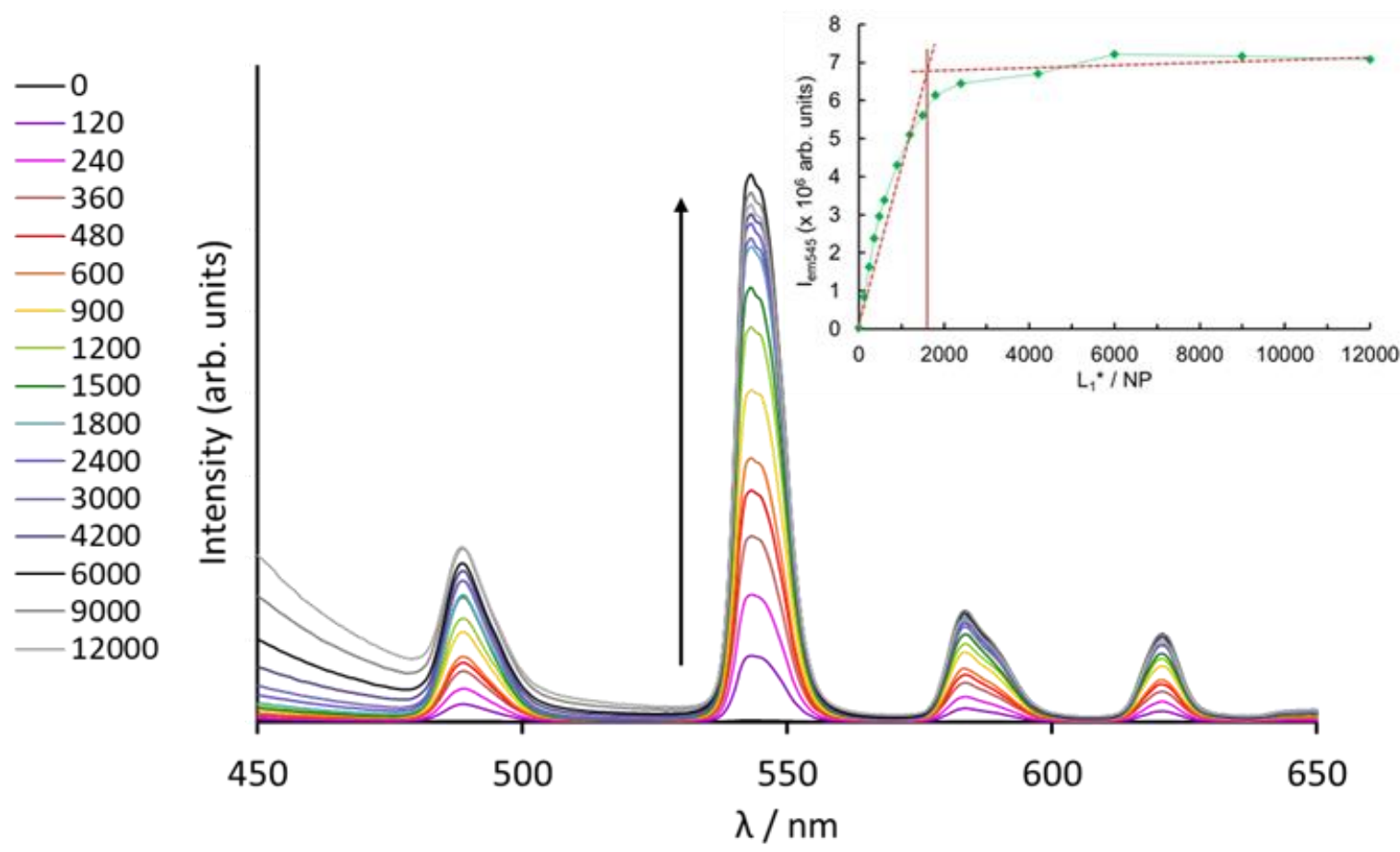
Figure 2. a) Evolution of the PL spectra $\left(\lambda_{\mathrm{exc}}=337 \mathrm{~nm}\right)$ of a $1.7 \mathrm{nM}$ solution of $\mathrm{La}_{0.9} \mathrm{~Tb}_{0.1} \mathrm{~F}_{3}$ (Tris/ $\mathrm{HCl} 0.01 \mathrm{M}, \mathrm{pH}=7.0$ ) upon addition of $\mathrm{L}_{1}$ * (the number of $\mathrm{L}_{1} *$ per NP is indicated by the color code). Inset: Evolution of the Tb centred emission intensity at $545 \mathrm{~nm}\left({ }^{5} \mathrm{D}_{4} \rightarrow{ }^{7} \mathrm{~F}_{5}\right.$ transition) as a function of the $\left[\mathrm{L}_{1} *\right] /[\mathrm{NP}]$ ratio.

As can be observed in Figure 2, the addition of $\mathrm{L}_{1}{ }^{*}$ to the NPs' solution immediately leads to the observation of a strong PL arising from Tb emission with the typical emission bands corresponding to the ${ }^{5} \mathrm{D}_{4} \rightarrow{ }^{7} \mathrm{~F}_{\mathrm{J}}$ transitions at $485,545,590$ and $620 \mathrm{~nm}$, respectively for $J=6$ to 3 . One can also notice the presence of weak bands above $630 \mathrm{~nm}$ corresponding to $J=2,1$ and 0 . Interestingly, the presence of a residual fluorescence band, observed between 450 and $500 \mathrm{~nm}$, points to an imperfect $\mathrm{L}_{1}$ * to $\mathrm{Tb}$ energy transfer. The evolution of the $\mathrm{Tb}$ PL intensity as a function of the $\left[\mathrm{L}_{1} *\right] /[\mathrm{NP}]$ ratio (Inset of Figure 2), shows a strong initial increase followed by a plateau region. This final part corresponds to the saturation of the TbNP surface by a layer of ligands and additional ligands can no longer coordinate at the surface and do not result in further photosensitization of the Tb centred emission. Using the intercept of the lines plotted for the rising and the plateau parts of the Tb intensity curves, we determine full surface coverage at $\sim 1700 \mathrm{~L}_{1} * / \mathrm{NP}$. The luminescence quantum yield of a solution of Tb NPs coated with 2030 $\mathrm{L}_{1}$ * per NP was determined using an integration sphere and the brightness of the sample could be determined (see Figures $\mathbf{S 2 8}$ to $\mathbf{S 3 0}$ and full experimental details in the supplementary in formation section). A maximum brightness of $1.8 \times 10^{6} \mathrm{M}^{-1} \cdot \mathrm{cm}^{-1}$ was measured at ca $310 \mathrm{~nm}$, which makes these nanoparticles among the brightest lanthanide containing NPs, ${ }^{12}$ comparable to doped polymeric nanoparticles containing Ln complexes (brightness of $\left.4 \times 10^{7} \mathrm{M}^{-1} \cdot \mathrm{cm}^{-1}\right)^{3}$ with the unique additional feature that they can be bio-functionalized.

In order to bioconjugate the TbNPs, the activated ligands can be labeled to various biological molecules of interest via their amine $\left(\mathrm{L}_{1} *\right)$ or thiol $\left(\mathrm{L}_{2} *\right)$ functionalities. The preparation of functional NP-bioconjugates can be challenging when the biomolecules are relatively large, i.e. similar size to the NPs, and therefore we selected two prominent examples, namely streptavidin (sAv) and antibodies (AB). SAv has a very strong interaction with biotin, which is frequently exploited for the design of biosensors. ${ }^{[16]}$ Matuzumab is a humanized monoclonal $\mathrm{AB}$ that binds with strong affinity to EGFR, which is known to be upregulated in different types of cancers. ${ }^{[17]}$ 
NP bioconjugation and FRET biosensing. An important method for biomolecular quantification in solution is FRET, which exploits the proximity between an energy donor and an energy acceptor upon biological recognition. ${ }^{[18]}$ We therefore challenged our TbNP bioconjugates with a prototypical FRET assay, in which the biomolecular recognition between TbNP-sAv and the biotinylated dye ATTO 610 (A610B) was monitored by TbNP-to-A610B FRET. While A610B was commercially available (cf. Scheme S1, Supplementary Information for the chemical structure of A610B), we prepared TbNP-sAv bioconjugates as detailed in the Experimental Section (Supplementary Information). Labeling of sAv with the photosensitizing ligands $\mathrm{L}_{1}$ * (determined by UV-Vis absorption spectroscopy, Figure 3) resulted in an average value of $1.0 \pm 0.1 \mathrm{~L}_{1}$ per $\mathrm{sAv}$. Addition of $\mathrm{L}_{1}-\mathrm{sAv}$ to TbNPs resulted in a maximum labeling ratio of $\sim 66 \mathrm{sAv}$ per TbNP, as determined by increasing Tb PL intensities with increasing amounts of $\mathrm{L}_{1}$-sAv, which showed an inflection point corresponding to the presence of $\sim 66 \mathrm{~L}_{1}$ sAv per TbNP (Figure S31, Supplementary Information). Considering the size of the tetrameric streptavidin protein (ca. $5 \mathrm{~nm}$ in diameter), ${ }^{[19]}$ it is not surprising that the number of $\mathrm{L}_{1}-\mathrm{sAv}$ per NP is largely inferior to that observed for the activated ligand alone.

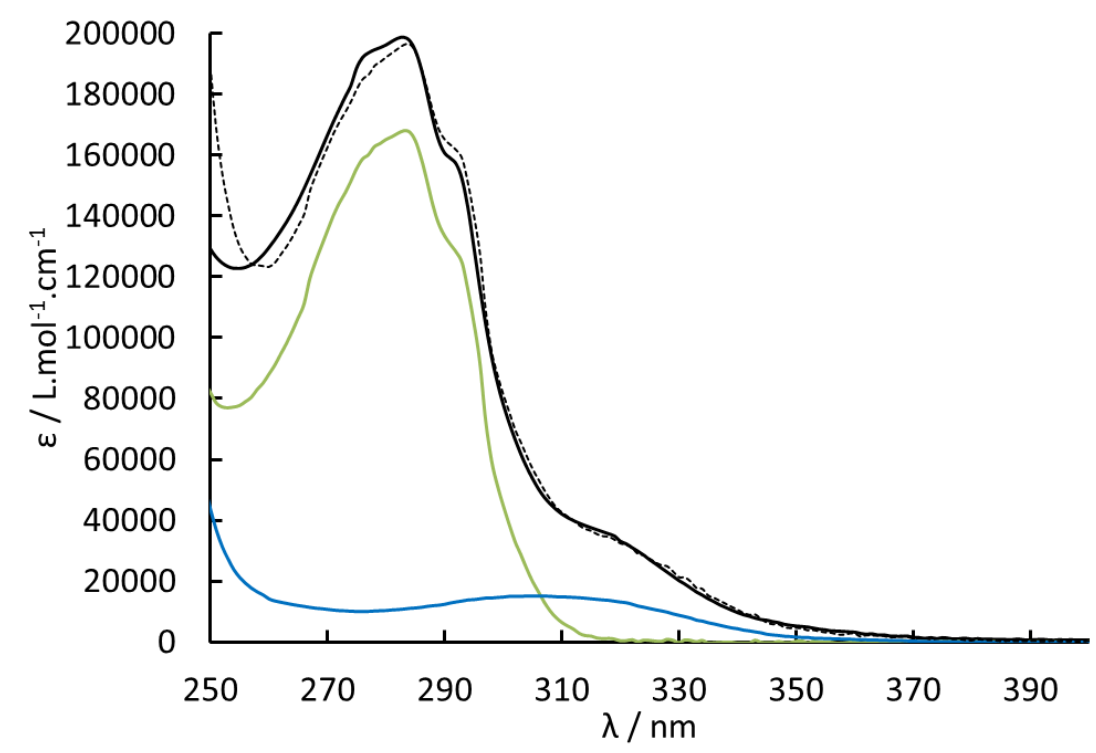

Figure 3. UV-Vis absorption spectra of $\mathrm{sAv}$ (green), $\mathrm{L}_{1}$ * (blue), $\mathrm{L}_{1}$ labeled $\mathrm{sAv}\left(\mathrm{L}_{1}\right.$-sAv, black) and the best fit for a linear combination of $\mathrm{sAv}$ and $\mathrm{L}_{1} *$ (dotted line).

For the FRET experiments, we used a conjugation ratio of $33 \mathrm{~L}_{1}$-sAv per TbNPs (half of the maximum conjugation ratio) to obtain many $\mathrm{sAv}$ on the TbNP surface without steric hindrance between the sAv, allowing for efficient biotin binding. Under these conditions, the 
PL lifetime of the Tb emission was composed of two main components (Figure 5), namely $\tau_{1}$ $=0.66 \mathrm{~ms}$ (amplitude fraction of $18 \%$ ) and $\tau_{2}=2.07 \mathrm{~ms}$ (amplitude fraction of $82 \%$ ), which we attributed to $\mathrm{Tb}$ ions at the very interface of surface and environment ( $\tau_{1}$ is shorter due to PL quenching by the aqueous solvent) and $\mathrm{Tb}$ ions close to the surface but not in direct contact with the environment $\left(\tau_{2}\right)$. As all of these ions were sensitized by the surface ligands, we assumed that they can also engage in FRET to surface-attached dyes, and we used the amplitude-averaged lifetime $(\langle\tau\rangle=1.8 \pm 0.1 \mathrm{~ms})$ as the Tb-donor lifetime. Taking into account a radiative lifetime of $\mathrm{Tb}$ of $4.75 \mathrm{~ms},{ }^{[19]}$ this value resulted in a donor PL quantum yield of $\Phi_{\mathrm{Tb}}$ $=1.8 / 4.75=0.38 \pm 0.03$. Figure S31 (Supplementary Information) shows the spectral overlap of TbNP-sAv emission and A610B absorption, which is an important requirement for FRET. Using equation $1,{ }^{[18]}$ with the orientation factor $\kappa^{2}=2 / 3$ (dynamic averaging as justified by the isotropic emission and long lifetime of $\mathrm{Tb}$ ), the refractive index $n=1.33$ (aqueous solution), the wavelength $\lambda$, the normalized (to unity over the integral) TbNP-sAv PL spectrum with intensity $I_{D}(\lambda)$, and the A610B absorption spectrum with molar extinction coefficient $\varepsilon(\lambda)$ (in $\mathrm{M}^{-1} \mathrm{~cm}^{-1}$ ) we obtained a Förster distance (donor-acceptor distance for $50 \%$ FRET efficiency) of $R_{0}=5.4 \pm 0.3 \mathrm{~nm}$.

$$
R_{0}=0.021\left(\kappa^{2} \Phi_{T b} n^{-4} \int I_{D}(\lambda) \varepsilon_{A}(\lambda) \lambda^{4} d \lambda\right)^{1 / 6}
$$

The FRET experiment consisted in adding increasing amounts of A610B to a solution of the TbNP-sAv and record the time-gated (from 0.08 to $1.08 \mathrm{~ms}$ after the excitation pulse) PL spectra after excitation into the $\mathrm{L}_{1}$ absorption band at $337 \mathrm{~nm}$. Notably, A610B was also excited at this wavelength. However, the time-gated detection mode suppressed the short-lived (nanosecond range) fluorescence of directly excited A610B and detected only the long-lifetime PL components of Tb donor PL and FRET-sensitized A610 acceptor PL, which possessed the same PL decay time as the FRET-quenched Tb donor. ${ }^{[18 a, 21]}$ Interaction of TbNP-sAv with A610B resulted in a close proximity between Tb donors and A610 acceptors and concomitant quenching of Tb PL and sensitization of A610 PL (in the 620 to $700 \mathrm{~nm}$ region), as shown in Figure 4. TbNP PL decreased almost linearly until $\mathrm{A} 610 \mathrm{~B} / \mathrm{sAv}=3$ and remained constant for higher ratios (Figure S33b, Supplementary Information). Although sAv can bind up to four biotins, sAv was attached to the TbNP surface, which limited the maximum amount of bound A610B to three and additional A610B did not result in further quenching. For FRET-sensitized A610B PL, the picture was slightly different because there was a linear intensity increase up to $\mathrm{A} 610 \mathrm{~B} / \mathrm{sAv}=1.5$ followed by a decrease between 1.5 and 3, after which A610 PL remained at 
a minimum level (Figure S33a, Supplementary Information). The strong PL quenching of A610B after only 1.5 A610B per sAv and the low PL intensity of A610B in general (compared to the strong PL quenching of $\mathrm{Tb}$ ) was most probably related to self-quenching, which is a frequently encountered phenomenon when high numbers of dyes are attached to the surface of a NP (1.5 A610B/sAv corresponds to $\sim 50$ A610B per TbNP, which contain $\sim 33 \mathrm{sAv}$ on their surface) and is caused by an increased probability of homo-FRET between the dyes in combination with the formation of non-fluorescent dimers of acceptor dyes that serve as energy trap states. ${ }^{[22]}$ To confirm that the FRET signals resulted from A610B-sAv binding, the same experiment was performed with TbNPs coated with the same number of $\mathrm{L}_{1} *$ ligands alone (without sAv). Neither Tb FRET-quenching nor A610B sensitization could be found in these control experiments (Figure S35, Supplementary Information).

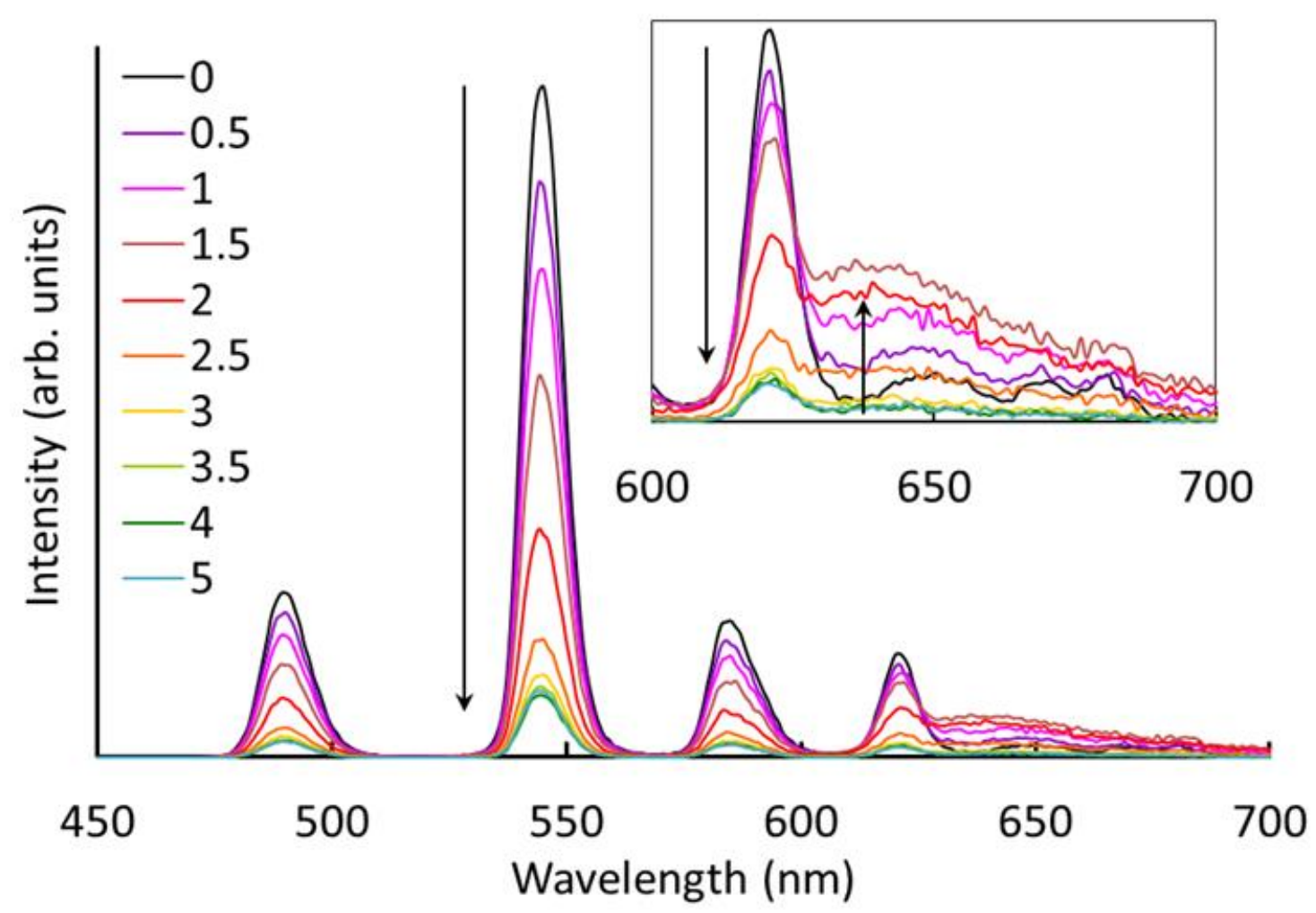

Figure 4. Time-gated PL spectra of the TbNP-sAv ([NP] $=1.6 \mathrm{nM}$ and A610B upon addition of different equivalents of A610B (number of equivalents per sAv are indicated by different colors, $\lambda_{e x c}=337 \pm 5 \mathrm{~nm}$, delay time of $80 \mu \mathrm{s}$, integration time of $\left.1 \mathrm{~ms}\right)$. Inset: zoom of the 600 $-700 \mathrm{~nm}$ range. (Figure S34 in Supplementary information, shows the deconvoluted TbNP and A610B PL spectra). 
In parallel to spectroscopic measurements, time-resolved PL decays of the TbNP donor (measured at $545 \pm 2.5 \mathrm{~nm}$ ) and of the A610 acceptor (measured at $637.0 \pm 2.5 \mathrm{~nm}$ ) were analyzed (Figure 5). Similar to the time-gated intensity results (Figure 4), the Tb donor curves (Figure 5a) decreased in both intensity and decay time until circa 3 A610B/sAv (and were more or less constant for higher ratios) and the A610 acceptor curves (Figure 5b) increased in intensity until $c a$. 1.5 A610B/sAv (and decreased to background levels for higher ratios). In addition to the background of Tb PL (black curve in Figure 5b), which decreased with increasing A610B/sAv ratios, the acceptor decay curves showed FRET-sensitized PL of A610 (faster decay contribution until $c a .1 .5 \mathrm{~ms}$, which is clearly above the Tb background PL). This A610 PL in the hundreds of microsecond range is clear evidence for FRET-sensitization via TbNPs as the intrinsic PL lifetime of A610 is in the nanosecond range.
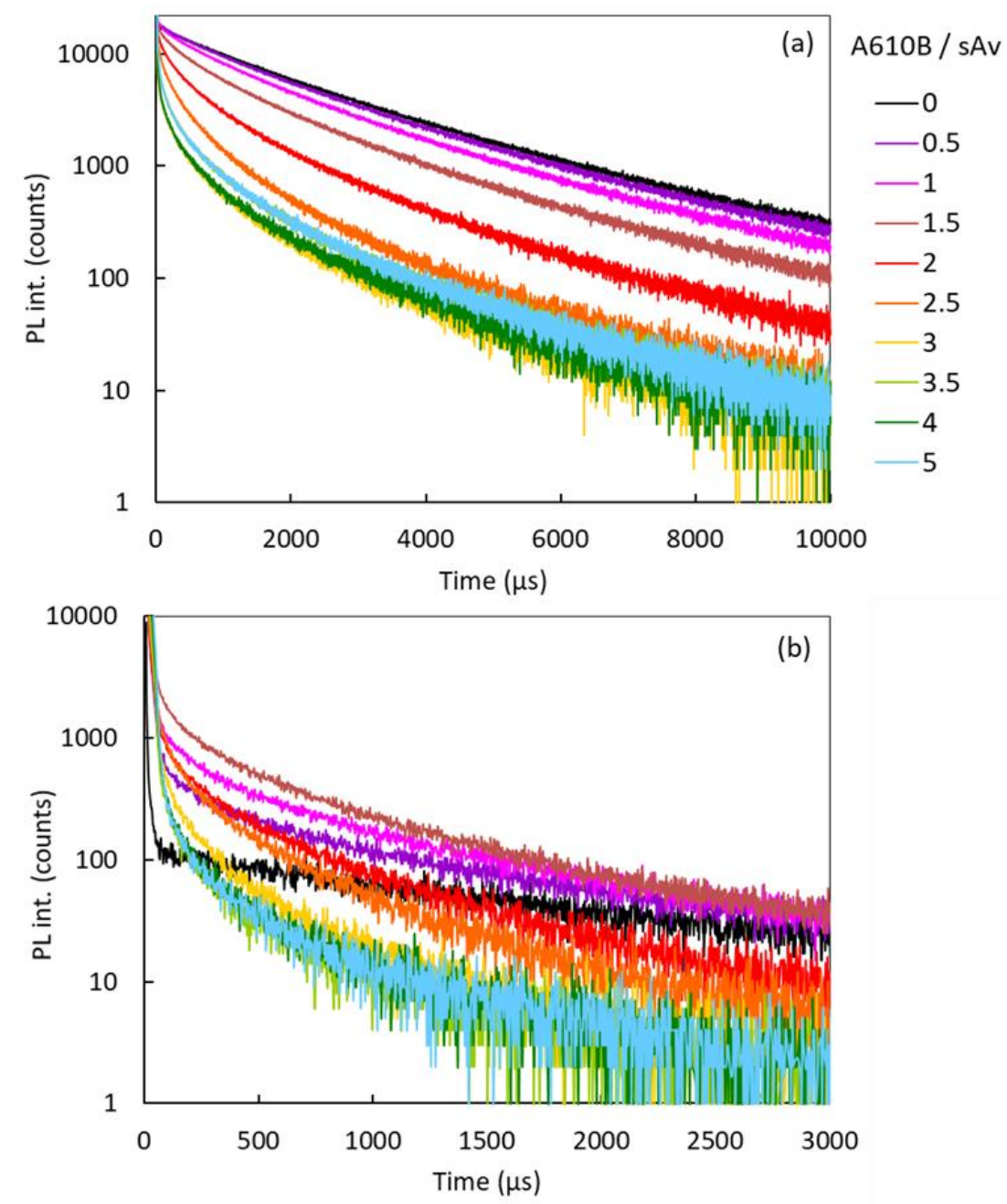
Figure 5. PL intensity decays (in Log units) of TbNP donors (a, $\lambda_{e m}=545.0 \pm 2.5 \mathrm{~nm}$ ) and A610 acceptors $\left(b, \lambda_{e m}=637.0 \pm 2.5 \mathrm{~nm}\right.$ ) for different ratios of A610B per sAv (ratios and color code shown on the right of graph a) upon pulsed excitation $\left(\lambda_{e x c}=337 \pm 5 \mathrm{~nm}\right)$.

Owing to the relatively weak and self-quenched FRET-sensitized PL of A610, its timegated intensities and time-resolved decays could not be used for distance estimations by FRET. However, the FRET-quenched Tb PL intensities and decays provided very useful data for quantifying Tb-donor to A610-acceptor distances. The FRET-efficiency ( $E_{\text {FRET }}$ ) of an emitting $\mathrm{Tb}^{3+}$ ions (sensitized by the sAv-attached ligand $\mathrm{L}_{1}$ ) depends on the number of acceptors $(a)$ and can be calculated by equation 2 , which assumes the same donor-acceptor distance $(R)$ for all acceptors: ${ }^{16 \mathrm{a}}$

$$
E_{F R E T}=\frac{a R_{0}{ }^{6}}{a R_{0}{ }^{6}+R^{6}}
$$

$E_{\text {FRET }}$ can also be calculated by donor PL intensities $(I)$ and decay times $(\tau)$ in the absence (subscript D) and in the presence (subscript DA) of the acceptor:

$$
\begin{aligned}
& E_{F R E T}=1-\frac{I_{D A}}{I_{D}} \\
& E_{F R E T}=1-\frac{\tau_{D A}}{\tau_{D}}
\end{aligned}
$$

Combining equations 2 and 3 allows for calculating the donor-acceptor distance $R$ by the Tb PL intensities (Figure 4) and decays (Figure 5 and Table S1 Supporting Information):

$$
\begin{aligned}
& R=R_{0}\left(a \frac{I_{D A}}{I_{D}-I_{D A}}\right)^{1 / 6} \\
& R=R_{0}\left(a \frac{\tau_{D A}}{\tau_{D}-\tau_{D A}}\right)^{1 / 6}
\end{aligned}
$$

Equation 4 must take into account that a maximum of three A610B can bind to one sAv on the TbNP surface $(a \leq 3)$, which means that $a=3$ is constant for all A610B/sAv $\geq 3$. For a correct determination of $R$, a few other considerations are necessary. PL intensity measurements quantify both FRET-quenched and non-quenched Tb PL (they cannot be distinguished in the spectra). Thus, equation 3 a determines an apparent FRET efficiency that takes into account 
donor-acceptor pairs as well as free donors (unquenched by FRET to the acceptor). For low $\mathrm{A} 610 \mathrm{~B} / \mathrm{sAv}$ ratios with a significant fraction of unquenched $\mathrm{Tb}^{3+}$ ions, the apparent FRET efficiency is significantly lower than the actual FRET efficiency for each donor-acceptor pair, which, in turn, is the correct FRET efficiency for calculating the donor-acceptor distance. The best solution for determining a donor-acceptor distance with Tb PL intensities is to use $\mathrm{A} 610 \mathrm{~B} / \mathrm{sAv}$ ratios $\geq 3$ because for these cases the TbNP surface is saturated with A610 acceptors and both $E_{\mathrm{FRET}}$ and $R$ are constant (Figure S36, Supplementary Information). Under these conditions, the average donor-acceptor distance was $R=4.5 \pm 0.3 \mathrm{~nm}$, which is in very good agreement with the dimensions of $\mathrm{sAv}$ in the solid state $\left(5.5 \times 5.8 \times 4.8 \mathrm{~nm}^{3}\right)^{[19]}$ and the structure (including the linker between biotin and A610) of A610B (Scheme S1, Supplementary Information).

The advantage of PL lifetime data is the concentration independence and that decay times from non-quenched and FRET-quenched donors can be distinguished. Therefore, the FRET-quenched decay times provide a FRET efficiency solely for donor-acceptor pairs, which can then be used for calculating the correct average donor-acceptor distance $R$. Using a previously developed and tested method for fitting multiexponential FRET decays for distance analysis, ${ }^{[23]}$ we fitted the TbNP PL decays from Figure 5 to obtain average Tb donor decay times $\left(\tau_{\mathrm{D}}\right)$ and FRET decay time $\left(\tau_{\mathrm{DA}}\right)$ that could be used to calculate the average donoracceptor distance $R$ using equation $4 \mathrm{~b}$ (Figure S37 and Table S1, Supplementary Information). Because the PL decay curves of 0.5 and $1 \mathrm{~A} 610 \mathrm{~B} / \mathrm{sAv}$ are very similar to the unquenched TbNP decay curve, these were not taken into account for calculating the average distance (fit results are nevertheless shown in Figure S37 and Table S1, Supplementary Information). All the other seven decay curves were analyzed and resulted in an average donor-acceptor distance of $R=$ $4.6 \pm 0.3 \mathrm{~nm}$, which is in excellent agreement with the FRET-saturated results from time-gated PL intensities (vide supra). Both time-gated PL intensity and time-resolved PL decays clearly demonstrate that this prototypical biotin-streptavidin binding system could be successfully used for analyzing biomolecular binding by FRET from TbNPs to dyes.

Fluorescence microscopy imaging of EGFR. Our second prototypical bioanalytical application consisted in the specific imaging of EGFR on cell membranes. Targeting EGFR and EGFR signaling are important for cancer research and many different cell lines have been investigated concerning their EGFR content and function. ${ }^{[24]}$ Bright and non-photobleaching nanoprobes for specific imaging of single, multiple, or clustered receptors from the epidermal 
growth factor family of receptor tyrosine kinases (EGFR, HER2, HER3, HER4) have the potential to significantly advance such cancer-related studies. ${ }^{[25]}$ One paramount requirement for a successful application of NP-based imaging agents is the functional conjugation with biological ligands (against the cell membrane receptor) that allow for specific targeting and the suppression of non-specific adsorption of the NPs to the cell, which often results in non-specific endocytosis of the NPs. ${ }^{[3,26]}$ We selected the AB Matuzumab, ${ }^{[27]}$ which is not only a very specific ligand against EGFR but can also serve as a prototypical system for demonstrating functional TbNP-AB conjugation in general. Another important prerequisite is a good dispersion of the AB-conjugated NPs during incubation with cells, such that they do not interact with each other (formation of NP clusters) but can accomplish specific EGFR imaging without deposition of NP aggregates around or on the cell surface. Finally, a highly interesting photophysical property of our TbNPs is their long PL lifetime (millisecond range), which can be exploited in time-gated imaging to suppress all autofluorescence background (which is in the nanosecond range). ${ }^{[28]}$ All time-gated images were taken on live cells and did not require delicate fixation protocols.

$\mathrm{L}_{2}-\mathrm{AB}$ conjugates were prepared by coupling the maleimide-activated ligand $\mathrm{L}_{2}{ }^{*}$ to thiols (reduced cysteines) on the $\mathrm{AB}$ and resulted in a labeling ratio of $\sim 7 \mathrm{~L}_{2}$ per $\mathrm{AB}$ (see Experimental Section, Supplementary Information) to assure efficient attachment of the ABs to the TbNP surface. To investigate the influence of AB-conjugation conditions for optimized EGFR imaging performance, we prepared TbNP-AB conjugates with $i$ ) different amounts of $\mathrm{L}_{2}-\mathrm{AB}$ conjugates, ii) $\mathrm{L}_{2}-\mathrm{AB}$ and additional photosensitizing ligands (to entirely cover the TbNP surface with photosensitizing ligands), and iii) under different conjugation conditions (different conjugation buffers). TbNP-AB conjugates were prepared by simple mixture of $\mathrm{L}_{2}-$ AB conjugates with TbNPs at ratios of $c a$ 20, 100, and 200 ABs per TbNP (see Experimental Section, Supplementary Information). In initial titration experiments (addition of $\mathrm{L}_{2}-\mathrm{AB}$ to TbNPs), we could show that up to $c a 200 \mathrm{~L}_{2}-\mathrm{AB}$ could be added to TbNPs to accomplish saturation of PL increase due to surface-attached photosensitizing ligands (Figure S38, Supplementary Information). We therefore assumed that $\mathrm{L}_{2}-\mathrm{AB}$ can efficiently bind to TbNPs until a maximum ratio of $\sim 200$ and that this value corresponded to $\sim 100 \%$ surface coverage. Relatively high ratios of ABs per TbNP were used because previous experiments (not shown) resulted in strong clustering of TbNP-AB conjugates at lower labeling ratios. For the 20AB/TbNP samples we also added non-activated photosensitizing ligands ( $\mathrm{L}_{\mathrm{CN}}$, Scheme $\mathbf{S 2}$, Supplementary Information) to investigate the influence of a complete coverage of the TbNP 
surface with photosensitizers on brightness and stability. While 20AB/TbNP and 100AB/TbNP samples were prepared in Tris buffer $(10 \mathrm{mM}, \mathrm{pH} 7.2)$ to match the conditions of the in-solution FRET experiments (vide supra), we used HEPES buffer $(10 \mathrm{mM}, \mathrm{pH} 7.0)$ for the highest labeling ratio of 200AB/TbNP. HEPES was selected because DLS measurements of bare TbNPs showed less aggregation compared to Tris. While TbNPs were stable over time (up to 60 days) and $\mathrm{pH}$ from 4 to 8 in $\mathrm{H}_{2} \mathrm{O}$, Tris resulted in significant aggregation (Figure S39). Sonicating TbNPs in HEPES for one hour resulted in small monodisperse TbNPs (Figure S40) and therefore, we used freshly sonicated TbNPs in HEPES for AB conjugation and performed imaging experiments directly afterwards.

To also evaluate the aggregation of the different TbNP-AB conjugates, we first performed DLS measurements in solution (Figure S41, Supplementary Information). These analyses showed that the hydrodynamic diameters of TbNP-AB conjugates became smaller for higher labeling ratios, that the $20 \mathrm{AB} / \mathrm{TbNP}$ and $100 \mathrm{AB} / \mathrm{TbNP}$ samples showed some clustering (additional species with very large hydrodynamic diameters above $4 \mu \mathrm{m}$ ), and that the addition of non-conjugated ligands $\left(20 \mathrm{AB} / \mathrm{TbNP}+\mathrm{L}_{\mathrm{CN}}\right)$ could not significantly reduce aggregation or the size of the main NP species. Time-gated PL imaging of A431 cells (Figure S42, Supplementary Information) confirmed strong clustering of the 20AB/TbNP samples on the cell surfaces. While the addition of $\mathrm{L}_{\mathrm{CN}}$ resulted in higher PL intensities and reduced clustering (smaller areas of PL spots), significantly better results were accomplished for the samples with higher labeling ratios. Previous studies showed that EGFR forms clusters of $\sim 150 \mathrm{~nm}$ in diameter on HeLa cells and that EGFR on highly EGFR-overexpressing A431 cells results in even stronger clustering and favors the assembly of NPs into larger clusters. ${ }^{[29]}$ Thus, we also expected a clustered fluorescence EGFR staining pattern for higher $\mathrm{AB} / \mathrm{TbNP}$ ratios but with significantly smaller clusters.

To investigate the possibility of detecting EGFR on cells with high (A431) ${ }^{[30]}$ and low (HeLa and COS-7) ${ }^{[31]}$ EGFR expression, we incubated those cells for 30 minutes with $20 \mathrm{AB} / \mathrm{TbNP}$ or $100 \mathrm{AB} / \mathrm{TbNP}$. Similar to non-targeted (pure TbNPs without bioconjugation) imaging, ${ }^{[26]}$ we required only low nanomolar concentrations $(1 \mathrm{nM}$ or $2 \mathrm{nM})$ of TbNP-AB conjugates to acquire sufficient PL signals for imaging EGFR on the cell membranes (Figures S43 and S44, Supplementary Information). Additionally, the stability of the TbNPs-AB in culture media was investigated by luminescence measurements, showing a gradual loss of $c a$ $75 \%$ intensity over the course of $15 \mathrm{~h}$, but with still remarkable intensities (Figure S45, Supplementary Information). For the lower EGFR-expressing HeLa and COS-7 cell lines, 
20AB/TbNP signals were below the detection threshold and could not image EGFR.,both conjugation ratios could be used for EGFR-targeted imaging on A431 cells. However, the $20 \mathrm{AB} / \mathrm{TbNP}$ conjugates showed significant clustering, whereas the $100 \mathrm{AB} / \mathrm{TbNP}$ conjugates clearly demonstrated the advantages of higher AB-conjugation ratios in terms of sensitivity. The different PL spot sizes in the 100AB/TbNP PL images (smaller for HeLa and COS-7 and larger for A431) also provided a good indication of the different EGFR expression levels in these cell lines.

To further investigate sensitivity, specificity (A431 cells vs EGFR-passivated A431 and EGFR-deleted NIH3T3 cell lines), and endocytosis of EGFR-bound TbNP-AB conjugates, we used the highest possible conjugation ratio of 200AB/TbNP. Time-gated PL imaging of A431 cells showed that different concentrations of the TbNP-AB conjugates resulted in different immunostaining patterns (Figure 6). Although the signals were relatively weak, $0.5 \mathrm{nM}$ TbNPs could still image EGFR on the cell membranes with high specificity. Using the same TbNP concentrations on NIH3T3 cells that did not express EGFR or on A431 cells that were passivated with non-conjugated $\mathrm{AB}$ (to saturate EGFR binding sites on the cell membrane) did not result in any PL signals (Figure S46, Supplementary Information). At higher concentrations, the EGFR on the cell membranes became more visible. For 2nM of TbNP-AB conjugates, almost the entire membrane could be stained, which showed the very high EGFR expression of A431 cells (Figure 6 bottom). These results demonstrated the importance of optimizing the $\mathrm{AB}$-conjugation conditions and that a maximum coverage of $\mathrm{AB}$ on the $\mathrm{TbNP}$ surface leads to TbNP-AB conjugates that can be applied for bright and targeted EGFR imaging with stable lanthanide emitters. 

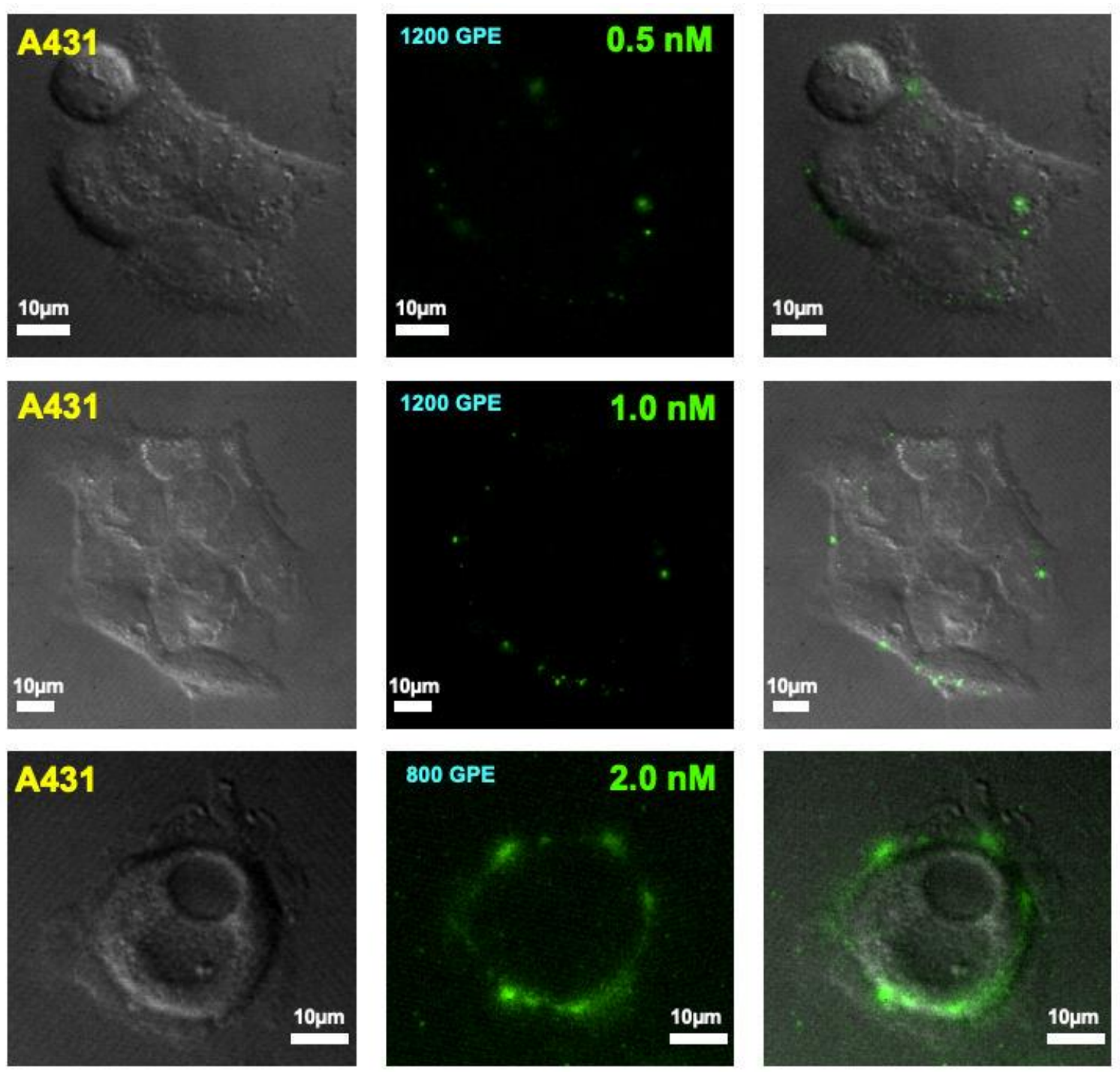

Figure 6. Time-gated PL imaging of EGFR on the membranes of A431 cells that were incubated for 30 minutes with different concentrations of $200 \mathrm{AB} / \mathrm{TbNP}$. The representative images show DIC transmission (left), time-gated PL (centre), and their overlay (right). PL of TbNPs is shown in green. GPE: Gates per exposure. Additional images are shown in Supporting Figure S47 (Supplementary Information).

Encouraged by the excellent EGFR imaging conditions, we aimed at investigating a possible cellular uptake (endocytosis) for intracellular trafficking of EGFR. ${ }^{[29 a, 32]}$ To localize the TbNP-AB conjugates on the cell envelope, we used co-staining with the plasma membrane marker MemBright-640 (MB-640). ${ }^{[33]}$ Several PL images were acquired at different heights of the cells (so called " $z$-stacking" from the ventral (bottom) to the dorsal (top) plasma membrane with $z$-steps of $0.22 \mu \mathrm{m}$ ). Movie S1 (Supplementary Information) shows the entire $z$-stack of PL images with TbNP-AB conjugates at distinct locations across three different cells. Figure 7 
shows representative sections of the $z$-stack with TbNP-AB inside the membrane, inside the cell, and outside the cell.
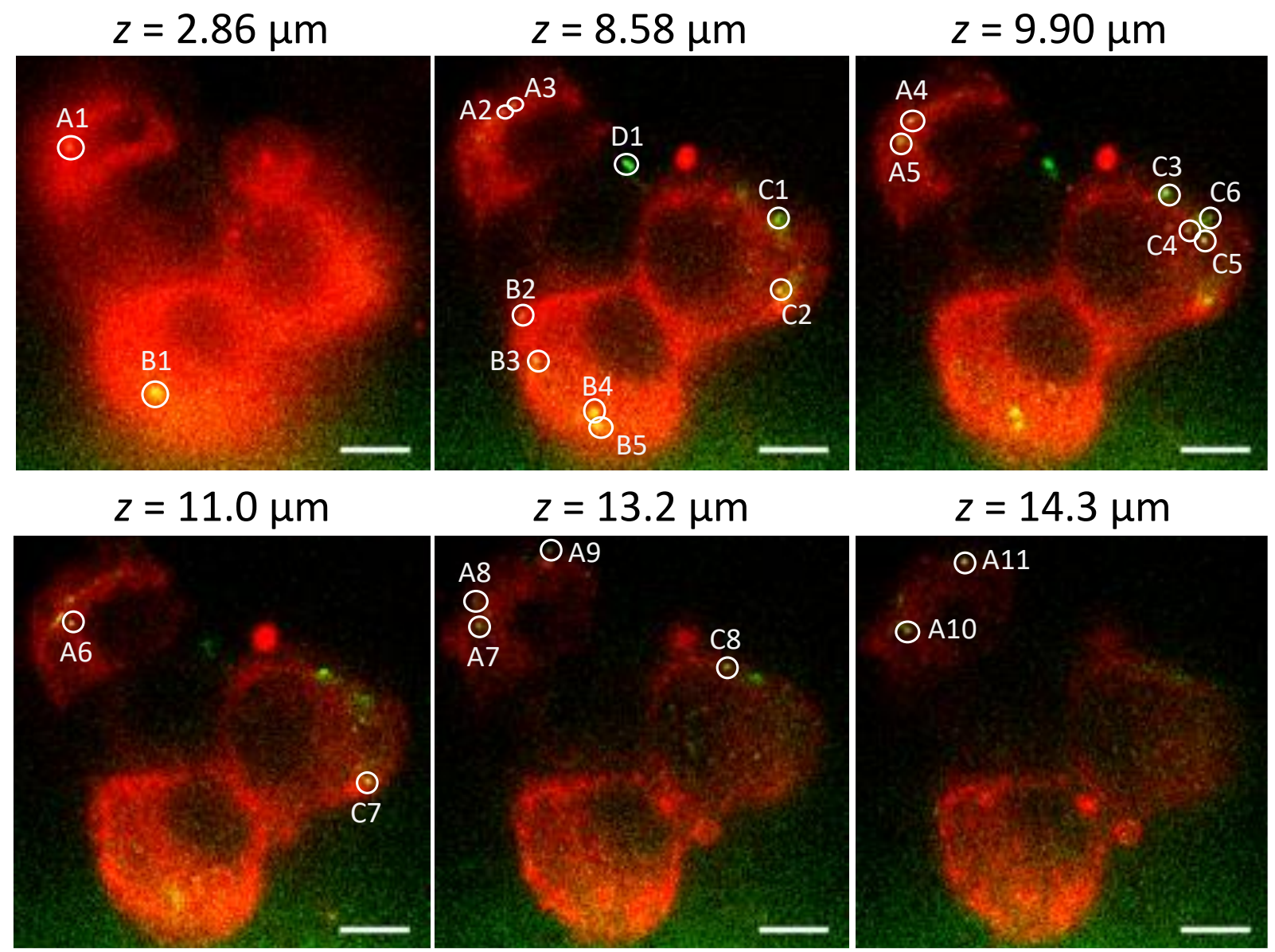

Figure 7. PL image sections ( $c f$. Movie S1, Supplementary Information for the entire z-stack) taken at different heights (bottom: $z=0$ ) of three representative cells (A, B, and C). The plasma membrane is colored in red and TbNP-AB in green. Colocalization of membrane and TbNP$A B$ is represented in yellow. Numbered areas show TbNP-AB at different locations within the cells. All areas were also analyzed with lateral sections ( $x z$ and $y z)$, which are shown in Figure S48, (Supplementary Information). Scale bar: $10 \mu \mathrm{m}$.

In the lowest $z$-section image $(z=2.86 \mu \mathrm{m})$ the two 2 yellow (colocalized TbNP-AB and MB$640 \mathrm{PL}$ ) points (A1 and B1) indicate that TbNP-AB are localized in the ventral membrane. In the second image $(z=8.58 \mu \mathrm{m})$ almost all TbNP-AB (with the exception of $\mathrm{C} 1$ and $\mathrm{D} 1$ ) are colocalized with the membrane (yellow spots). Taking into account that this section is close to the center of the cell, the TbNP-ABs are most probably localized in the side membranes of the cells. In contrast, $\mathrm{C} 1$ is not colocalized with the membrane (green), indicating that the TbNP$\mathrm{AB}$ has not yet adhered to the plasma membrane. D1 (also green) is a cluster of TbNP-AB 
outside the cell (floating in the medium). Slightly higher in the cells $(z=9.90 \mu \mathrm{m}) \mathrm{TbNP}-\mathrm{AB}$ A4 and A5 (yellow) are probably colocalized with side membrane, C3 is outside the cell but close to the membrane (bound to extracellular EGFR) and C4, C5, and C6 appear to be inside the cell (internalized very recently and located just below the membrane), which confirms findings that EGFR already internalizes after 15 to 20 minutes at $37^{\circ} \mathrm{C}^{[32 \mathrm{a}]}$ Similar to the above interpretation we can assign A6 and C7 $(z=11.0 \mu \mathrm{m})$ to the side membrane, A7, A8 and C8 ( $z$ $=13.2 \mu \mathrm{m})$ to the dorsal membrane, and A9, A10, and A11 $(z=14.3 \mu \mathrm{m})$ to be outside and close to the dorsal membrane (bound to extracellular EGFR). This analysis of only 25 PL spots and in only three cells can merely provide a broad picture of the different possible localizations of TbNP-AB in and on the cells $(64 \%$ colocalized with the plasma membrane, $20 \%$ on the extracellular side of the membrane, $12 \%$ internalized inside the cells, and $4 \%$ in the medium outside the cells). However, it suggests that TbNP-AB conjugates are capable of specifically recognizing EGFR without significantly hindering its internalization. Indeed, incubation of A431 cell lines with TbNP-AB (200AB/TbNP) for 5 hours revealed clearly different staining patterns (Figure 8) with PL signals originating from inside the cells (beyond the membranes and around the nuclei), which is another good evidence that the binding of TbNP-AB conjugates to the transmembrane EGFR leads to endocytosis and internalization of the entire EGFR-TbNP$\mathrm{AB}$ complexes. While our results are only a proof-of-concept and did not aim at the investigation of intracellular signalling, the results demonstrate that TbNP-AB conjugates may become useful for intracellular live cell bioanalysis. Deeper investigation with many more cells, higher spatial resolution (confocal or super resolution), and at different TbNP-AB incubation times (kinetic study) would be necessary to fully understand the dynamic cellular uptake behaviour of EGFR-attached TbNP-AB.
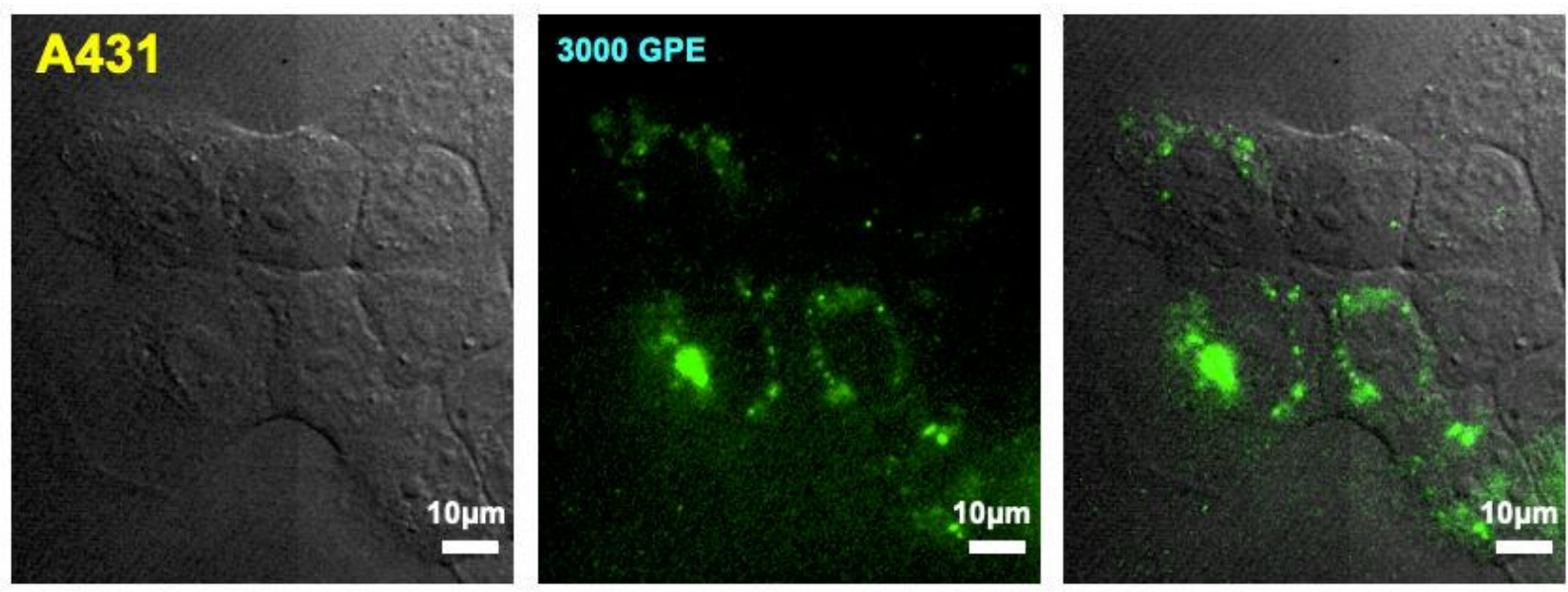
Figure 8. Time-gated PL imaging of EGFR on and in A431 cells that were incubated for 5 hours with $2 \mathrm{nM}$ of $200 \mathrm{AB} / \mathrm{TbNP}$. The representative images show DIC transmission (left), time-gated PL (center), and their overlay (right). PL of TbNPs is shown in green. GPE: Gates per exposure. Additional images are shown in Figure $\mathbf{S 4 9}$ (Supplementary Information).

Supplementary Information. Full synthetic details for the ligands and conjugation experiments, details of the spectroscopic titrations, FRET experiments, cell culture and microscopy can be found in the supplementary information section.

\section{Conclusion}

Lanthanide-doped NPs combine photophysical advantages, such as high brightness, high photostability, line-like spectra, long PL lifetimes, and biocompatibility, with large surfaces for the attachment of various biomolecules. One of the most important prerequisites for implementing such NPs into actual bioanalytical applications is a straightforward design of functional NP-bioconjugates. In our present study, we developed a new type of ligand that can be used for both photosensitization of $\mathrm{Tb}$ surface ions and bioconjugation. This simultaneous photosensitization and bioconjugation approach resulted in extremely bright and stable TbNP bioconjugates, which we investigated in two prototypical bioanalytical applications. Timeresolved PL spectroscopy was used to show that streptavidin-coated TbNPs could specifically recognize biotinylated ATTO610 dyes in aqueous solution, which resulted in efficient Tb-todye FRET, demonstrating that these bright $\mathrm{Tb}$ surface emitters are capable of quantitatively analyzing ligand-receptor binding in solution, which is a frequently applied concept in clinical diagnostics. Time-gated PL microscopy was used to demonstrate the application of TbNPantibody conjugates for ligand-receptor binding on cell membranes and a possible implementation into the investigation of transmembrane receptor trafficking. Different cell lines with strong, weak, and no expression of EGFR as well as EGFR-passivated cells were incubated with Matuzumab-functionalized TbNPs and the antibody-TbNP labeling ratio was optimized for specific recognition of extracellular EGFR. TbNP PL images revealed the formation of EGFR clusters and time-dependent internalization of TbNP-Matuzumab-EGFR complexes that started after only 30 minutes of incubation and demonstrated the capability of TbNP-antibody conjugates to be specifically endocytosed by A431 cells. 
The two representative applications for in-solution FRET bioassays and in-situ live cell imaging of ligand-receptor binding and endocytosis demonstrate that surface-photosensitized lanthanide-doped NPs can be efficiently bioconjugated and used in actual biological applications. While UV excitation of the surface-photosensitized TbNPs will certainly limit the penetration depth for in-vivo or tissue studies, the irradiation doses used for our live-cell timegated PL imaging approach are extremely low $\left(\sim 0.5 \mu \mathrm{J} / \mathrm{cm}^{2}\right.$, which is more than $10^{6}$ times lower than conventional UV irradiation doses used for cellular investigations) and the TbNPs were found to be non-cytotoxic over at least 72 h. ${ }^{[26]}$ Time-gated PL imaging for autofluorescencebackground detection, extremely high brightness, photophysical stability, and the use of very low concentrations for high signal-to-background ratios are other specific benefits of surfacephotosensitized LnNPs. Our bifunctional ligands accomplished the highly important first step of translating surface-photosensitized LnNPs into useful nanobioconjugates for efficient biological recognition with bright PL signals for in-solution sensing and receptor-targeted cell imaging, which is one of the most critical prerequisites for implementing bright and stable lanthanide-NPs as standard PL probes into diverse clinical and bioanalytical research studies.

Acknowledgements. PolyDTech SA (Strasbourg, France) is gratefully acknowledged for the gift of TbNPs. We thank A. Klymchenko and M. Collot for providing MemBright-640. The French Agence Nationale de la Recherche is acknowledged for financial support (ANR project Neutrinos $\left.n^{\circ} 16-C E 09-0015-02\right)$. We thank the Imagerie-Gif core facility (supported by ANR11-EQPX-0029/Morphoscope, ANR-10-INBS-04/FranceBioImaging, and ANR-11-IDEX0003-02/ Saclay Plant Sciences) for TEM measurements.

\section{References}

1/ a) P.D. Howes, R. Chandrawati, M. M. Stevens, Science, 2014, 346, 1247390. b) A. M. Coto-García, E. Sotelo-González, M. T. Fernández-Argüelles, R. Pereiro, J. M. CostaFernández, A. Sanz-Medel, Anal. Bioanal. Chem. 2011, 399, 29. c) N. Hildebrandt, O. Tagit. J. Nanosci. Nanotech. 2018, 18, 6671. 
a) W. R. Algar, A. J. Tavares, U. J. Krull, Anal. Chim. Acta 2010, 673, 1. b) R.C. Somers, M.G. Bawendi, D.G. Nocera, Chem. Soc. Rev. 2007, 36, 579. c) N. Hildebrandt, C. M. Spillmann, W. R. Algar, T. Pons, M. H. Stewart, E. Oh, K. Susumu, S. A. Díaz, J. B. Delehanty, I. L. Medintz. Chem. Rev. 2017, 117, 536. d) D. Geißler, N. Hildebrandt, Anal. Bioanal. Chem. 2016, 408, 4475. e) K.D. Wegner, N. Hildebrandt, Chem. Soc. Rev. 2015, 44, 4792. e) Z. Lia, J.-J. Zhu, Analyst 2013, 138, 2506. f) I.V. Martynenko, A.P. Litvin, F. Purcell-Milton, A.V. Baranov, A.V. Fedorov, Y.K. Gun'ko, J. Mater. Chem. B 2017, 5, 6701. g) J. Zhou, Y. Yang, C. Zhang, Chem. Rev. 2015, 115, 11669.

3/ M. Cardoso Dos Santos, A. Runser, H. Bartenlian, A. M. Nonat, L.J. Charbonnière, A. S. Klymchenko, N. Hildebrandt, A. Reisch, Chem. Mater. 2019, 31, 4034.

4/ a) K. Li, B. Liu, B. Chem. Soc. Rev. 2014, 43, 6570. b) A. Kaeser, A.P.H. Schenning, Adv. Mater. 2010, 22, 2985.

5/ a) Y.I. Park, K. T. Lee, Y. D. Suh, T. Hyeon, Chem. Soc. Rev., 2015, 44, 1302. b) S. F Himmelstoß, T. Hirsch, Methods Appl. Fluoresc. 2019, 7, 022002. c) F. Wang, X. Liu, Chem. Soc. Rev. 2009, 38, 976. c) U. Resch-Genger, H.H. Gorris, Anal. Bioanal. Chem. 2017, 409, 5855. d) U. Resch-Genger, H.H. Gorris, Anal. Bioanal. Chem. 2017, 409, 5875.

6/ a) A. Escudero, A. I. Becerro, C. Carrillo-Carrión, N. O. Núñez, M. V. Zyuzin, M. Laguna, D. González-Mancebo, M. Ocaña, W. J. Parak, Nanophotonics, 2017, 6, 881. b) D. Tu, W. Zheng, P. Huang, X. Chen, Coord. Chem. Rev. 2019, 378, 104. c) H. Dong, S.-R. Du, X.Y. Zheng, G.-M. Lyu, L.-D. Sun, L.-D. Li, P.-Z. Zhang, C. Zhang, C.-H. Yan Chem. Rev. 2015, 115, 10725. d) C. Bouzigues, T. Gacoin, A. Alexandrou. ACS Nano 2011, 5, 8488. e) M. Sy, A. Nonat, N. Hildebrandt, L.J. Charbonnière, Chem. Commun. 2016, 52, 5080-5095.

7/ a) S. Tang, M. Moayeri, Z. Chen, H. Härmä, J. Zhao, H. Hu, R.H. Purcell, S.H. Leppla, I.K. Hewlett, Clin. Vaccine Immunol. 2009, 16, 408. b) H. Härmä, T. Soukka, T. Lövgren, Clin. Chem. 2001, 47, 561. c) Y. Chen, Y.M. Chi, H.M. Wen, Z.H. Lu, Anal. Chem. 2007, 79, 960.

8/ a) A. Davies, D.J. Lewis, S.P. Watson, S.G. Thomas, Z. Pikramenou, Proc. Natl. Acad. Sci. U.S.A. 2012, 109, 1862. b) K.L. Wong, G.L. Law, M.B. Murphy, P.A. Tanner, W.T. Wong, P.K.S. Lam, M.H.W. Lam, Inorg. Chem. 2008, 47, 5190. c) W. Di, J. Li, N. Shirahata, Y. Sakka, M. Willinger, N. Pinna, Nanoscale 2011, 3, 1263. d) V. Väisänen, H. Härmä, H. Lilja, A. Bjartell, Luminescence 2000, 15, 389. e) K. Kattel, J.Y. Park, W. Xu, H.G. Kim, E.J. Lee, B.A. 
Bony, W.C. Heo, Y. Chang, T.J. Kim, J.Y. Do, K.S. Chae, Y.W. Kwak, G.H. Lee, Colloids Surf. A 2012, 394, 85. f) Q. Zhao, Y.H. Liu, Y.F. Cao, W. Lv, Q. Yu, S.J. Liu, X.M. Liu, M. Shi, W. Huang, Adv. Opt. Mater. 2015, 3, 233. g) W. Sun, J.B. Yu, R.P. Deng, Y. Rong, B. Fujimoto, C.F. Wu, H.J. Zhang, D.T. Chiu, Angew. Chem., Int. Ed. 2013, 52, 11294.

9/ J.-C. G. Bünzli, Chem. Rev. 2010, 110, 2729.

10/ S. I. Weissman, J. Chem. Phys. 1942, 10, 214.

11/ a) S. Li, X. Zhang, Z. Hou, Z. Cheng, P. Ma, J. Lin, Nanoscale 2012, 4, 5619. b) J. Zhang, C. M. Shade, D. A. Chengelis, S. Petoud, J. Am. Chem. Soc. 2007, 129, 14834. c) L. J. Charbonnière, J.-L. Rehspringer, R. Ziessel, Y. Zimmermann, New J. Chem. 2008, 32, 1055.

12/ J. Goetz, A. Nonat, A. Diallo, M. Sy, I. Sera, A. Lecointre, C. Lefevre, C. F. Chan, K.L. Wong, L. J. Charbonnière, ChemPlusChem 2016, 81, 526.

13/ K. Sapsford, W.R. Algar, L. Berti, K. Boeneman Gemmill, B.J. Casey, E. Oh, M.H. Stewart, I.L. Medintz, Chem. Rev. 2013, 113, 1904.

14/ a) A. D’Aléo, J. Xu, K. Do, G. Muller, K. N. Raymond, Helv. Chim. Acta, 2009, 92, 2439. b) A. P. S. Samuel, E. G. Moore, M. Melchior, J. Xu, K. N. Raymond, Inorg. Chem. 2008, 47, 7535 .

15/ B. Horstmann, M. Korbus, T. Friedmann, C. Wolff, C. M. Thiele, F.-J. Meyer-Almes, Bioorg. Chem. 2014, 57, 155.

16/ C.M. Dundas, D. Demonte, S. Park, Appl. Microbiol. Biotech. 2013, 97, 9343.

17/ S. Sebastian, J. Settleman, S. J. Reshkin, A. Azzariti, A. Bellizzi, A. Paradiso, Biochim. Biophys. Acta - Rev. Canc. 2006, 1766, 120.

18/ a) I. Medintz, N. Hildebrandt, editors: FRET - Förster Resonance Energy Transfer. From Theory to Applications", Wiley-VCH, Germany 2014, ISBN 978-3-527-32816-1; b) W.R. Algar, N. Hildebrandt, S.S. Vogel, I.L. Medintz, Nature Methods 2019, 16, 815.

19/ W.A. Hendrickson, A. Pahler, J. L. Smith, Y. Satow, E.A. Merritt, R. P. Phizackerley, Proc. Nat. Acad. Sci. 1989, 86, 2190.

20/ G. Stein, E. Würzberg, J. Chem. Phys. 1975, 62, 208. 
21/ N. Hildebrandt, K. D. Wegner, W. R. Algar, Coord. Chem. Rev. 2014, 273-274, 125.

22/ C. Chen, B. Corry, L. Huang, N. Hildebrandt, J. Am. Chem. Soc. 2019, 141, 11123.

23/ a) N. Hildebrandt. How to apply FRET - From experimental design to data analysis. In: I. Medintz and N. Hildebrandt, editors: FRET - Förster Resonance Energy Transfer. From Theory to Applications", Wiley-VCH, Germany 2014, ISBN 978-3-527-32816-1; b) K. D. Wegner, F. Morgner, E. Oh, R. Goswami, K. Susumu, M. H. Stewart, I. L. Medintz, N. Hildebrandt Chem. Mater. 2014, 26, 4299. c) C. Chen, C. Midelet, S. Bhuckory, N. Hildebrandt, M. H. V. Werts, J. Phys. Chem. C 2018, 122, 17566. d) J. Guo, X. Qiu, C. Mingoes, J.R. Deschamps, K. Susumu, I.L. Medintz, N. Hildebrandt, ACS Nano 2019, 13, 505.

24/ a) N. Normanno, A De Luca, C. Bianco, L. Strizzi, M. Mancino, M.R. Maiello, A. Carotenuto, G. De Feo, F. Caponigro, D.S. Salomon, Gene 2006, 366, 2. b) O.M. Fischer, S. Hart, A. Gschwind, A. Ullrich, Biochem. Soc. Trans. 2003, 31, 1203. c) J. D. Orth, E. W. Krueger, S. G. Weller, M. A. McNiven. Canc. Res. 2006, 66, 3603.

25/ H. S. Afsari, M. Cardoso dos Santos, S. Lindén, T. Chen, X. Qiu, P. M. P. van Bergen en Henegouwen, T. L. Jennings, K. Susumu, I. L. Medintz, N. Hildebrandt, L. W. Miller, Science Adv. 2016, 2, e1600265.

26/ a) M. Cardoso Dos Santos, J. Goetz, H. Bartenlian, K.-L. Wong, L.J. Charbonnière, N. Hildebrandt, Bioconjugate Chem. 2018, 29, 1327.

27/ a) C. Kollmannsberger, M. Schittenhelm, F. Honecker, J. Tillner, D. Weber, K. Oechsle, L. Kanz, C. Bokemeyer, Ann. Oncol. 2006, 17, 1007. b) K. Kuester, A. Kovar, C. Lüpfert, B. Brockhaus, C. Kloft, Brit. J. Canc. 2008, 98, 900.

28/ a) M. Cardoso Dos Santos, N. Hildebrandt, Trends Anal. Chem. 2016, 84, 60-71; b) J. Zwier, N. Hildebrandt. Time-gated FRET detection for multiplexed biosensing. In: Chris D. Geddes, editor: Reviews in Fluorescence 2016. Springer International 2017, ISBN 978-3-31948259-0.

29/ a) A. Abulrob, Z. Lu, E. Baumann, D. Vobornik, R. Taylor, D. Stanimirovic, L.J. Johnston, J. Biol. Chem. 2010, 285, 3145. b) J. Wang, X. Yu, S. V. Boriskina, B. M. Reinhard, Nano Letters 2012, 12, 3231. 
31/ a) A. Sorkin, L. K. Goh, Exp. Cell Res. 2009, 315, 683. b) F. Zhang, S. Wang, L. Yin, Y. Yang, Y. Guan, W. Wang, H. Xu, N. Tao, Anal. Chem. 2015, 87, 9960.

32/ a) A. D. Sorkin, L. V. Teslenko, N. N. Nikolsky, Exp. Cell Res. 1988, 175, 192. b) A. Sorkin, E. Kornilova, L. Teslenko, A. Sorokin, N. Nikolsky, Biochim. Biophys. Acta - Mol. Cell Res. 1989, 1011, 88.

33/ M. Collot, P. Ashokkumar, H. Anton, E. Boutant, O. Faklaris, T. Galli, Y. Mély, L. Danglot, A.S. Klymchenko, Cell Chem. Biol. 2019, 26, 600. 